\title{
Do study circles and a nutritional care policy improve nutritional care in a short- and long-term perspective in special accommodations?
}

\author{
Albert Westergren* and Gita Hedin \\ Department of Clinical Nursing Science, School of Health and Society, Kristianstad University, Kristianstad, Sweden
}

\section{Abstract}

Background: Disease-related malnutrition is a major health problem in the elderly population and management issues are under-explored.

Objectives: What is the prevalence of undernutrition-risk (UN-risk), underweight, and overweight in special accommodations (SAs)? Do study circles and a nutritional care policy (NCP) improve the precision in nutritional care (NC) and decrease the prevalence of under- and overweight in a short- and/or long-term perspective?

Design: Quasi-experimental pre- and post-intervention design with three experimental groups and one control group (CG).

Setting: SAs.

Participants: In 2005 (Time 1 - T1), 1726 (90.4\%) residents agreed to participate; in 2007 (Time 2 - T2), 1,526 (81.8\%); and in 2009 (Time 3 - T3), 1,459 (81.3\%) residents participated.

Interventions: Experimental groups: between T1 and T2 the first period of study circles was conducted in one municipality; between T2 and T3 a second period of study circles in another municipality was conducted; after T1 a NCP was implemented in one municipality. CG: residents in three municipalities.

Measurements: Under- and overweight were defined based on BMI. Risk of undernutrition was defined as involving any of: involuntary weight loss, low BMI, and/or eating difficulties. The 'precision in NC' describes the relationship between nutritional treatment (protein- and energy-enriched food (PE-food) and/or oral supplements) and UN-risk.

Results: The prevalence of UN-risk varied between 64 and $66 \%$, underweight between 25 and $30 \%$, and overweight between 30 and 33\% in T1-T3. At T2 the prevalence of underweight was significantly lower in the first period study circle municipality, and at T3 in the second period study circle municipality compared to in the CG. The precision in NC was higher in a short-term perspective in the study circle municipalities and both in a short- and long-term perspective in the NCP municipality. At T3 between 54 and $70 \%$ of residents at UNrisk did not receive PE-food or oral supplements.

Conclusions: Study circles give positive short-term effects and a NCP gives positive short- and long-term effects on NC. Whether a combination of study circles and the implementation of a NCP can give even better results is an area for future studies.

Keywords: education; policy, undernutrition, overweight, prevalence, special accommodation, quality improvement

Received: 17 June 2010; Revised: 19 August 2010; Accepted: I September 2010; Published: 24 September 2010

$\mathrm{M}$ alnutrition (undernutrition, UN, and overweight) is a major health problem in the elderly population living in special accommodations (SAs) (long-term care facilities) $(1,2)$, but this has until recently received very little attention, in contrast to the interest in and focus on malnutrition in hospital populations. Especially the management issues connected to malnutrition have been under-explored.

It is important to educate the staff in special accomodations (SAs) about simple interventions that could improve nutritional status (3), especially as it has been found that a majority of residents at undernutrition-risk 
(UN-risk) do not receive any form of nutritional support $(2,4)$. Two basic nutritional interventions are to provide protein- and energy-enriched food (PE-food) and oral supplements, which can improve nutritional status and reduce mortality in elderly people at UN-risk $(3,5-8)$. Educational programmes focusing on nutrition can improve the ability of nursing staff to ensure adequate food intake for their residents $(9,10)$. For instance, it was recently shown in two studies that educational programmes according to the study circle methodology improved the nutritional care (NC) and outcome in SAs $(2,11)$. In addition, in geriatric home settings with a higher rate of training in nutritional screening and management, the risk of UN among residents was found to be lower (12).

Besides educational programmes, the development of policies is also emphasised in order to tackle malnutrition. Thus, the management of SAs should acknowledge their responsibility in relation to nutritional screening, assessment, and care (13-15). Systematic nutritional assessment followed up by individualised care planning has been shown to result in weight stability (15). The management also needs to implement quality indicators that can be assessed through regular audits, controls, and feedback from the residents in order to keep the standards high (13). However, to our knowledge there are no studies that have focused, in a long-term perspective, on how well $\mathrm{NC}$ is targeted to residents after implementation of study circles or a nutritional care policy (NCP).

Through an intervention, study circles, aiming at increasing the staff's knowledge about eating and nutrition, and having the staff set goals for how to positively change the possibility for the elderly to get properly nourished, it was recently shown that more residents at nutritional risk were provided PE-food and that fewer had low BMI after the intervention in comparison to a control group (CG), i.e. no intervention municipalities. In the same study, one municipality implemented a NCP focusing on detecting and managing residents at nutritional risk. In the NCP municipality the precision in NC did not significantly differ in comparison to the other municipalities (2). The positive results found after implementing study circles needs to be replicated in another municipality and the long-term effects remain to be explored, both regarding study circles and regarding the NCP.

The aim of this study was to explore the prevalence of UN-risk, underweight, and overweight among residents in SAs. An additional aim was to explore whether study circles and a NCP improve the precision in NC and decrease the prevalence of under- or overweight in a short- and/or long-term perspective in comparison to a CG.

\section{Present investigation}

\section{Materials and methods}

Design

Quasi-experimental pre- and post-intervention design with three experimental groups and one CG.

Subjects

All SAs ( $n=65$ units, cf. long-term care homes) within six municipalities, belonging to the same geographical region in southern Sweden, were involved in three pointprevalence studies in November 2005, October 2007, and October 2009. In 2005, 1,726 (90.4\%) out of 1,910 residents agreed to participate; in 2007, 1,526 (81.8\%) out of 1,866 ; and in $2009,1,459(81.3 \%)$ out of 1,795 residents participated. Thus, the study includes 4,711 residents in total.

Overall, the mean age was slightly higher among those not participating $(n=860)$ compared to those included $(n=4711)$ (86.2, SD 8.4 vs. 85.8, SD 7.7, $p<0.0005)$. There was no significant difference regarding gender between those included and those not participating.

Data collection

After gaining informed consent, students, clinical tutors, and staff collected the data during 5 days (from Monday to Friday) in order to be able to assess all residents.

Undernutrition (UN) and overweight

UN-risk was defined as the occurrence of any of the three criteria: involuntary weight loss, underweight (BMI below limit $-<20$ if $\leq 69$ years, $<22$ if $\geq 70$ years) and/ or eating difficulties according to the Minimal Eating Observation Form - Version II (MEOF-II) (16) based on Swedish recommendations for detecting UN-risk $(1,17)$. Little risk for UN was defined as one criterion fulfilled, moderate risk if two, and high risk if three criteria were fulfilled.

MEOF-II includes three components of eating (ingestion, deglutition, and energy/appetite). Each component includes three aspects of eating. Thus, in total MEOF-II includes nine aspects of eating. Each aspect was coded as zero, having no problems, or one, having problems (16). The presence of one or more problems in any of the nine aspects of eating was regarded as a risk criterion for UN.

Overweight was graded based on BMI (if $\leq 69$ years: BMI 25 or above: if $\geq 70$ years: BMI 27 or above) and so was obesity (if $\leq 69$ years: BMI $30-39$ : if $\geq 70$ years: BMI 32-41) and severe obesity (if $\leq 69$ years: $\mathrm{BMI}>40$ : if $\geq$ 70 years: BMI >42) (1). Height and weight were measured using the standard equipment available at the particular units. Information about unintentional weight loss was gained from the resident or estimated from previous weight. 
Precision in nutritional care (NC)

PE-food is food that is smaller in volume than the regularly served meals, but has the same or higher content of protein and energy compared to the ordinary hospital food on the menu. 'Oral supplements' include oral nutritional supplements such as protein and energy drinks given in addition to and chiefly between the main meals. Supplements do not include pharmacological therapy or drug supplements with multivitamin and mineral pills.

In this study ' $\mathrm{NC}$ ' has been simplified to include PEfood and/or oral supplements. The 'precision in NC' describes the relationship between nutritional treatment (PE-food and/or oral supplements) and UN-risk (2). The precision is here divided into:

- Whole sample o perfect targeting (at UN-risk and provided with treatment AND not at UN-risk and not provided with treatment).

- At UN-risk and

o provided with treatment, perfect targeting; o not provided with treatment, under-treatment.

- Not at UN-risk and

o not provided with treatment, perfect targeting;

o provided with treatment, over-treatment.

Interventions

The municipalities were divided into four groups: CG (three municipalities), study circles intervention between years 2006 and 2008, period one (SC\#1, one municipality), study circles intervention between years 2007 and
2009, period two (SC\#2, one municipality), and NCP implemented in 2006 (NCP, one municipality) (Fig. 1).

Control group (CG) municipalities. There was no specific major nutritional intervention in the three $\mathrm{CG}$ municipalities other than that the results from the nutritional surveys in 2005, 2007, and 2009 were sent to each unit with a possibility for the staff to compare their own unit's results with the total results from the other municipalities. The same feedback was given to the NCP and study circle municipalities. Through meetings four times each year in a nutritional network (the Network for Eating and Nutrition in North-East Skåne, NEN-NES) between the municipalities, hospitals and primary health care, no major changes (catering, nursing system or organisational) in the CG came to the authors' knowledge.

Study circles, first period, 2006-2008, SC\#1. In one municipality, 71 study circles focusing on eating and nutrition, each consisting of about eight staff members (in total 592 participants), were carried out between 2006 and 2008. Each study circle met for three afternoons $(3 \mathrm{~h}$ each time). The most common combination of staff in each circle was one person working in the kitchen, who usually was also the circle leader, and seven auxiliary nurses or nurse assistants. No dietitian was involved in the study circles, as there were none employed in the municipality until the last year (2).

Study circles, second period, 2007-2009, SC\#2. In another municipality, about 30 study circles also focusing on eating and nutrition, each consisting of about ten
Intervention

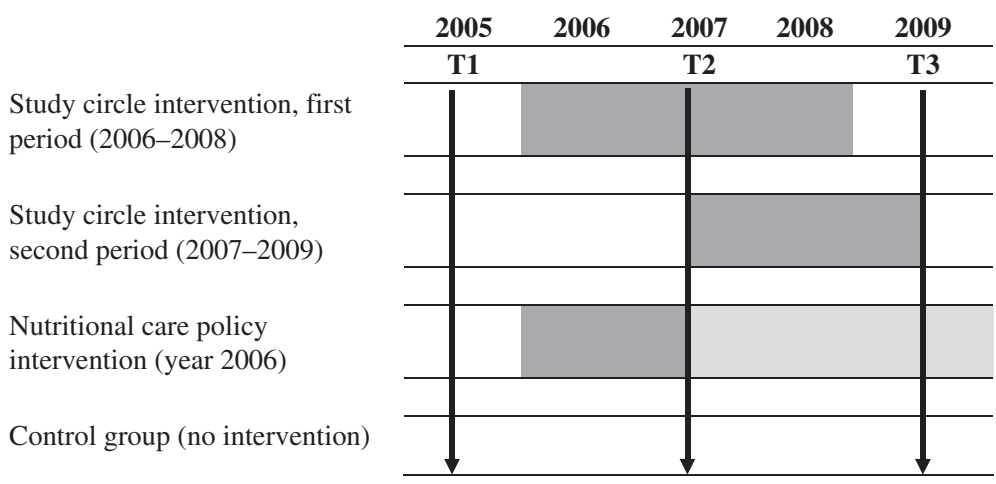

White fields $=$ no major active work with the intervention

Dark grey $=$ intensive work with the intervention or implementation

Light grey $=$ less intensive work with the intervention

Arrows $=$ point-prevalence studies and feedback

Fig. 1. Point in time for interventions and surveys. 
staff members (in total about 300 participants), were carried out between 2007 and 2009. In this municipality, each study circle met for three to six afternoons $(2.5-3 \mathrm{~h}$ each time). The most common combination of staff in each circle was the same as in SC\#1.

Nutritional care policy (NCP). After the first nutritional survey, an NCP was politically anchored in one municipality and thereafter implemented in the organisation without having been planned within the study framework. The NCP focused on screening, treatment, and nutritional quality indicators (such as "no more than $11 \mathrm{~h}$ without eating at night time').

Ethics

The ethics for conducting scientific work was followed. This study was approved in each municipality. The residents were asked for informed consent. Both verbal and written information was given and residents were guaranteed anonymity, i.e. no personal identification numbers or names were collected. As the study was a part of an overall quality development project, no formal approval by an ethical committee was required, according to the Swedish Act concerning the Ethical Review of Research Involving Humans (18).

Analysis

Parametric and non-parametric statistics were used depending on the level of data and based on unpaired comparisons between two or more groups. First comparisons were made over time and then intervention groups were compared with the CG. The following tests were applied: Chi-square test, Kruskal Wallis test, and oneway ANOVA. The level of statistical significance was set at $p<0.05$. When multiple post-hoc comparisons were made a Bonferroni correction (alpha divided by three comparisons, giving a reduced $p<0.017$ ) was used to avoid mass significance (type I or alpha error) $(19,20)$. Analyses were performed using PASW Statistics 18.0.

\section{Results}

The prevalence of moderate/high UN-risk in 2005 (Time 1 - T1), 2007 (Time 2-T2), and 2009 (Time 3-T3) was $26.2 \%, 29.8 \%$, and $25.6 \%$. If including also those at low UN-risk, the prevalence was $63.7 \%, 65.7 \%$, and $65.4 \%$. The prevalence of underweight was $30.1 \%$ (T1), 26.1\% (T2), and 25.4\% (T3). The prevalence of overweight was 30.0\% (T1), 33.0\% (T2), and 33.1\% (T3) (Table 1).

There were no significant differences between residents participating in T1-T3 regarding, gender, eating difficulties, nutritional risk (low, moderate, and high), and need of eating assistance. Residents were older in T3 than in T1 $(p<0.0005)$. There were more residents with underweight in $\mathrm{T} 1$ than in $\mathrm{T} 3$ (30.1 and 25.4\%, respectively, $p=0.007)$. Fewer residents were reported to have unintentional weight loss in $\mathrm{T} 1(19.4 \%)$ than in $\mathrm{T} 2(35.8 \%, p<0.0005)$ and in T3 $(30.6 \%, p<0.0005)$, and the difference was also significant when comparing the figures in T2 and T3 $(p=0.006)$. There was also an increase in the number of residents that was provided with PE-food from T1 $(4.5 \%)$ to T2 $(9.1 \%, p<0.0005)$ and from T1 to T3 $(14.3 \%, p<0.0005)$. The difference was also significant when comparing the figures between T2 and T3 $(p<0.0005)$. There was an increase in the number of residents that were provided with oral supplements from T1 $(11.2 \%)$ to T2 $(16.3 \%, p<0.0005)$ and from T1 to T3 $(19.7 \%)(p<0.0005)$. The difference was also significant when comparing the figures between T2 and T3 $(p=0.017)$ (Table 1).

Comparing the three interventions and the CGs at T1 regarding underweight and overweight showed no significant differences (Table 2).

In $\mathrm{T} 2$, there was significantly more with low BMI in the CG $(30.2 \%)$ in comparison to in the SC\#1 $(22.2 \%)$ and in the SC\#2 groups $(17.7 \%)(p=0.010$ and 0.012 , respectively) (Table 2 ).

In $\mathrm{T} 3$, there were more residents with low $\mathrm{BMI}$ in the $\mathrm{CG}(27.7 \%)$ in comparison to in the $\mathrm{SC} \# 2$ group $(15.6 \%)$ $(p=0.005)$ (Table 2).

There were no significant differences in the precision of nutritional care (NC) between the different groups at T1 (Table 3).

In $\mathrm{T} 2$, among those at UN-risk the perfect targeting (having UN and receiving NC) was higher in the SC\#1 and $\mathrm{PD}$ groups (31.1 and $34.6 \%$, respectively) compared to in the CG $(22.8 \%)$ ( $p=0.015$ and 0.009 , respectively). Correspondingly the under-treatment (having UN and not getting NC) differed in the same way (Table 3).

In $\mathrm{T} 3$, the perfect targeting in the whole sample was higher in the SC\#2 group $(65.2 \%)$ compared to in the CG $(52.0 \%)(p=0.004)$. Among residents at UN-risk the perfect targeting was higher in the SC\#2 (46.4\%) and in the PD groups $(44.4 \%)$ compared to in the CG $(30.5 \%)$ ( $p=0.004$ and 0.009 , respectively). Correspondingly, the under-treatment differed in the same way. Among residents at no UN-risk, the over-treatment in $\mathrm{NC}$ varied between 4.9 and $11.3 \%$ in T3. At T3 between 53.6 and $69.5 \%$ of residents at UN-risk did not receive protein and energy enriched food or oral supplements (Table 3).

\section{Discussion}

The positive short-term effects of study circles that have been described in a previous study (2) were replicated in this study. In addition, short- and long-term positive effects were found regarding the NCP intervention. More specifically, the study circle intervention in period one showed better precision in the provision of $\mathrm{NC}$ for residents at $\mathrm{UN}$ risk in comparison to the $\mathrm{CG}$ municipalities. There was also a lower prevalence of underweight in $\mathrm{T} 2$, positive 
Table 1. Characteristics of residents in special accommodations in 2005 (T1, $n=1726), 2007(\mathrm{~T} 2, n=1526)$, and 2009 $(\mathrm{T} 3, n=1459)$

\begin{tabular}{|c|c|c|c|c|}
\hline & TI & $\mathrm{T} 2$ & T3 & $P$-value \\
\hline \multicolumn{5}{|l|}{ Characteristics of residents } \\
\hline Age, mean (SD) & $85.4(7.7)$ & $85.8(7.6)$ & $86.5(7.9)$ & $0.043^{\mathrm{a}}$ \\
\hline$<70$ years $(\%)$ & 4.0 & 3.3 & 3.2 & 0.421 \\
\hline$>70$ years $(\%)$ & 96.0 & 96.7 & 96.8 & \\
\hline Gender, men (\%) & 31.0 & 32.1 & 32.3 & 0.689 \\
\hline \multicolumn{5}{|l|}{ Criteria for UN-risk (\%) } \\
\hline Having one or more eating difficulties according to MEOF-II & 53.4 & 52.3 & 52.9 & 0.890 \\
\hline Underweight & 30.1 & 26.1 & 25.4 & $0.009^{\mathrm{a}}$ \\
\hline Unintentional weight loss & 19.4 & 35.8 & 30.6 & $0.00 \mathrm{I}^{\mathrm{a}-\mathrm{c}}$ \\
\hline \multicolumn{5}{|l|}{ Fulfilling risk criteria (\%) } \\
\hline No criteria - no risk & 36.4 & 34.3 & 34.7 & 0.379 \\
\hline One criterion - low risk & 37.5 & 35.9 & 39.8 & \\
\hline Two criteria - moderate risk & 18.0 & 23.3 & 18.2 & \\
\hline Three criteria - high risk & 8.2 & 6.5 & 7.4 & \\
\hline Overweight (\%) & & & & 0.148 \\
\hline No overweight & 70.0 & 67.0 & 66.9 & \\
\hline Grade I, overweight & 21.4 & 24.3 & 23.5 & \\
\hline Grade 2, obesity & 8.3 & 8.5 & 8.9 & \\
\hline Grade 3, severe obesity & 0.2 & 0.3 & 0.3 & \\
\hline \multicolumn{5}{|l|}{ Nutritional care (\%) } \\
\hline Eating assistance & 50.5 & 48.8 & 48.3 & 0.442 \\
\hline PE-food & 4.5 & 9.1 & 14.3 & $0.000^{a-c}$ \\
\hline Oral supplements & 11.2 & 16.3 & 19.7 & $0.000^{a-c}$ \\
\hline
\end{tabular}

${ }^{\mathrm{a}} \mathrm{TI}$ differs from $\mathrm{T} 3$.

${ }^{\mathrm{b}} \mathrm{TI}$ differs from $\mathrm{T} 2$.

${ }^{\mathrm{C}} \mathrm{T} 2$ differs from $\mathrm{T} 3$.

Analyses: ANOVA, Chi-square test and Kruskal Wallis Test. $P$-values were considered significant if $<0.05$, and in post-hoc comparisons if $<0.017$ (Bonferroni correction). PE-food, protein and energy enriched food. Underweight, low BMI $<20$ (69 years or below), BMI $<22$ (70 years or older). Overweight: BMI 25-29 (69 years or below), BMI 27-3I (70 years or older). Obesity: BMI 30-39 (69 years or below), BMI 32-4I (70 years or older). Severe obesity: BMI $>40$ (69 years or below), BMI $>42$ (70 years or older).

results that did not remain significant in T3. However, these short-term effects were replicated with the study circle intervention in period two, in another municipality. In the municipality where a NCP was implemented, no significant differences were found in the number of residents with underweight, even though the same prevalence was achieved in T3 $(22.2 \%)$ as was found in the 'study circle period one municipality' in T2. However, the precision in $\mathrm{NC}$ in the NCP group was higher in both T2 and T3 in comparison to the $\mathrm{CG}$.

Data from the repeated cross-sectional surveys have been analysed both over time and by comparing the $\mathrm{CG}$ and intervention groups. The analysis over time was done in order to give a picture of the total number of residents with UN-risk, being underweight or overweight at the given points in time, answering the first research question. It was found that the prevalence of UN-risk and overweight was stable in T1-T3 while the prevalence of underweight decreased. A shortcoming with crosssectional point-prevalence studies is that the progression of malnutrition prevalence over time in the same individuals cannot be gauged. In a study by Wikby et al. (11) implementing a study circle intervention in resident homes, the same individuals were followed over 4 months. After 4 months the number of residents with UN decreased significantly from 20 to seven in the experimental group and not significantly from 17 to 10 in the CG (11). That study gives support for the claim that a study circle intervention can be effective, at least from a short-term perspective. Through comparing the controland intervention groups at the different time points, in this study, the method with repeated cross-sectional surveys with 2-year intervals was used to estimate the possible quality improvements from different interventions. By this approach we could answer the second research question, i.e. study circles give positive short- 
Table 2. Underweight and overweight in special accommodations in 2005 (T1), 2007 (T2), and 2009 (T3). Control group compared to intervention groups

\begin{tabular}{|c|c|c|c|c|c|}
\hline & \multirow[b]{2}{*}{ Control group } & \multicolumn{3}{|c|}{ Intervention groups } & \multirow[b]{2}{*}{$P$-value } \\
\hline & & Study circles first period & Study circles second period & Nutritional care policy & \\
\hline TI & $n=962$ & $n=467$ & $n=122$ & $n=175$ & \\
\hline Underweight (\%) & 29.9 & 31.2 & 30.3 & 28.6 & 0.929 \\
\hline Overweight (\%) & 28.6 & 31.2 & 38.5 & 28.6 & 0.137 \\
\hline$T 2$ & $n=871$ & $n=384$ & $n=102$ & $n=169$ & \\
\hline Underweight (\%) & 30.2 & 22.2 & 17.7 & 23.1 & $0.008^{\mathrm{a}, \mathrm{b}}$ \\
\hline Overweight (\%) & 29.7 & 34.8 & 37.5 & 39.4 & 0.065 \\
\hline T3 & $n=858$ & $n=307$ & $n=|4|$ & $n=153$ & \\
\hline Underweight (\%) & 27.7 & 26.8 & 15.6 & 22.1 & $0.028^{\mathrm{b}}$ \\
\hline Overweight (\%) & 30.6 & 31.9 & 38.3 & 36.4 & 0.338 \\
\hline
\end{tabular}

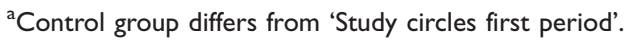

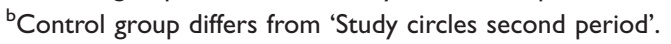

Analyses: Chi-square test. $P$-values was considered significant if $<0.05$, and in post-hoc comparisons if $<0.017$ (Bonferroni correction). Underweight, low BMI $<20$ (69 years or below), BMI $<22$ (70 years or older). Overweight, high BMI $>25$ (69 years or below), BMI $>27$ (70 years or older).

term effects and a NCP gives positive short- and longterm effects on NC. During the 2-year intervals new residents moved in, others moved out, and some died, a process that in a large-scale study like this might even out some possible negative aspects of not following the same individuals over time, i.e. the interaction between deteriorating health status, development of $\mathrm{UN}$, and needing NC. The mean age in the different years was about the same in the different intervention and CGs, which supports the idea of a general stability or homogeneity of the resident samples over the years (data not shown). Another advantage with the study design was that a pretest was conducted at baseline to detect whether there were signs of selection bias due to the distribution of residents in the different interventions and CGs. This pretest showed that the four groups were comparable in relation to the chosen variables, with one exception. Fewer residents were underweight at baseline (T2) in the second period of study circles compared to in the CG.

There was an increase in the prevalence of unintentional weight loss in the total sample, while there was a decrease in the number of residents with underweight over time. As discussed in a previous paper (2), this can be explained by an increased awareness among staff, since the first study in 2005, about the importance of following the weight development of the residents.

Another methodological shortcoming is that not all aspects of $\mathrm{NC}$ have been covered and thus the fairly positive changes achieved should not be interpreted by means of the increased precision in provision of $\mathrm{NC}$ alone. Most likely, also other multifaceted interventions such as well-established mealtime ambiance and family-style meals (21), planned within the study circles and in the NCP municipality, contributed to the positive outcome.

Besides the study circles and the NCP interventions it is important to bear in mind that all municipalities, i.e. all units, received feedback from the point-prevalence studies. This could be seen as an intervention, or as a base for working with quality improvement. However, this feedback was given to all units, even in the intervention municipalities, and is thus not likely to confound the results. However, it is important for the management to use quality indicators (13) that can be evaluated, for instance through point-prevalence studies measuring UN-risk and NC.

Regarding the provision of $\mathrm{NC}$, here limited to include PE-food and oral supplements, also other alternatives can be offered. For instance, in two of the municipalities the residents could choose from a menu of 12 different alternatives to oral supplements that each had a content corresponding to about one oral supplement (219-290 $\mathrm{kcal}$, and $6-10 \mathrm{~g}$ of protein). This was simplified in the registration as 'oral supplements or similar from menu'. This way of managing snacks between meals is supported by a recently published study (22) where 'snack foods' in between meals were found to be more effective (increased caloric intake) and less expensive than oral supplements.

The prevalence of underweight (low BMI) in this study was similar to what has been found in some other studies. In this study the prevalence of underweight, using ageadapted cut-offs (BMI $<20$ for younger and $<22$ for older) decreased from $30 \%$ to $26 \%$ and finally to $25 \%$. In Danish nursing homes (23) the prevalence of underweight was 33\% (BMI cut-off 20) and in a study from France it was $25 \%$ (BMI cut-off 21). In the French long-term care 
Table 3. The precision (in percent) in nutritional care (NC), i.e. provided protein and energy enriched food and/or oral supplements, in relation to nutritional risk (no versus low/moderate/high risk of undernutrition, UN) in special accommodations in 2005 (T1), 2007 (T2), and 2009 (T3). Control group compared to intervention groups.

\begin{tabular}{|c|c|c|c|c|c|}
\hline & \multirow[b]{2}{*}{ Control group } & \multicolumn{3}{|c|}{ Intervention groups } & \multirow[b]{2}{*}{$P$-value } \\
\hline & & $\begin{array}{l}\text { Study circles } \\
\text { first period }\end{array}$ & $\begin{array}{l}\text { Study circles } \\
\text { second period }\end{array}$ & $\begin{array}{l}\text { Nutritional } \\
\text { care policy }\end{array}$ & \\
\hline \multicolumn{6}{|l|}{ TI } \\
\hline Whole sample & $n=962$ & $n=467$ & $n=122$ & $n=175$ & \\
\hline Perfect targeting (UN and $\mathrm{NC} /$ no $\mathrm{UN}$ and no $\mathrm{NC}$ ) & 47.4 & 45.7 & 52.5 & 52.0 & 0.365 \\
\hline At UN-risk & $n=605$ & $n=305$ & $n=80$ & $n=112$ & \\
\hline Perfect targeting (UN and NC) & 18.1 & 18.8 & 27.8 & 26.8 & $0.047^{\mathrm{a}}$ \\
\hline Under-treatment (UN and no NC) & 81.9 & 81.2 & 72.2 & 73.2 & \\
\hline No UN-risk & $n=357$ & $n=162$ & $n=42$ & $n=63$ & \\
\hline Perfect targeting (no UN and no NC) & 97.4 & 96.2 & 100 & 96.8 & 0.588 \\
\hline Over-treatment (no UN and provided NC) & 2.6 & 3.8 & 0.0 & 3.2 & \\
\hline \multicolumn{6}{|l|}{$T 2$} \\
\hline Whole sample & $n=87 \mid$ & $n=384$ & $n=102$ & $n=169$ & \\
\hline Perfect targeting (UN and NC/no UN and no NC) & 45.9 & 52.6 & 52.0 & 55.7 & $0.037^{\mathrm{a}}$ \\
\hline At UN-risk & $n=590$ & $n=239$ & $n=66$ & $n=108$ & \\
\hline Perfect targeting (UN and NC) & 22.8 & 31.1 & 28.8 & 34.6 & $0.016^{\mathrm{b}, \mathrm{c}}$ \\
\hline Under-treatment (UN and no NC) & 77.2 & 68.9 & 71.2 & 65.4 & \\
\hline No UN-risk & $n=281$ & $n=145$ & $n=36$ & $n=61$ & \\
\hline Perfect targeting (no UN and no NC) & 94.5 & 88.8 & 94.4 & 93.3 & 0.209 \\
\hline Over-treatment (no UN and provided NC) & 5.5 & 11.2 & 5.6 & 6.7 & \\
\hline \multicolumn{6}{|l|}{ T3 } \\
\hline Whole sample & $n=858$ & $n=307$ & $n=|4|$ & $n=153$ & \\
\hline Perfect targeting (UN and $\mathrm{NC} /$ no $\mathrm{UN}$ and no NC) & 52.0 & 53.1 & 65.2 & 62.5 & $0.006^{\mathrm{d}}$ \\
\hline At UN-risk & $n=568$ & $n=210$ & $n=85$ & $n=90$ & \\
\hline Perfect targeting (UN and NC) & 30.5 & 35.6 & 46.4 & 44.4 & $0.004^{c, d}$ \\
\hline Under-treatment (UN and no NC) & 69.5 & 64.4 & 53.6 & 55.6 & \\
\hline No UN-risk & $n=290$ & $n=97$ & $n=56$ & $n=63$ & \\
\hline Perfect targeting (no UN and no NC) & 95.1 & 93.3 & 94.4 & 88.7 & 0.293 \\
\hline Over-treatment (no UN and provided NC) & 4.9 & 6.7 & 5.6 & 11.3 & \\
\hline
\end{tabular}

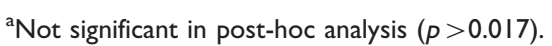

'Control group differs from 'Study circles first period'.

'Control group differs from 'Nutritional care policy'.

'Control group differs from 'Study circles second period'.

Analyses: Chi-square test. $P$-value was considered significant if $<0.05$, and in post-hoc comparisons if $<0.017$ (Bonferroni correction).

homes, the proportion with underweight was as high as $31 \%$ (12). In the French study $21 \%$ needed eating assistance in nursing homes and 58\% in long-term care homes, while in this study the equivalent number was about $50 \%$. This indicates that the residents in Swedish SAs are closer to the level of dependency found in the French long-term care homes. Dependency for eating indicates that the resident is in the category of severe dependency (24). In another study among nursing-home residents in the USA, $25 \%$ of residents were underweight (BMI cut-off 19.4) (25). Bearing in mind that the studies use different cut-offs, have studied populations with different degrees of dependency, and have been conducted in different years, the prevalence found in the last years in this study was similar or more likely lower than what was found in the Danish, French, and American studies.

A NCP that is anchored politically and by the management, and later implemented in the care settings, following a 'top-down' process, seemed to have more long-term positive effects than the study circles focusing on eating and nutrition. Within the study circles the participants had discussions and set meaningful and locally adapted goals relating to the residents' nutrition 
without necessarily focusing on the screening and management of UN. Thus, the study circle intervention could be said to follow a 'bottom-up' process and gave short-term positive effects, as has also been shown previously $(2,11)$. Kitson and colleagues (26) state that a 'successful implementation' (SI) of new ideas (evidence, guidelines, etc.) is a function (f) of the interrelations between three key elements - evidence (E), context (C), and facilitation $(F): S I=f(E, C, F)$. Thus, interventions considering these three elements might be successful in increasing the precision in the nutritional interventions, which will in turn hopefully decrease the number of residents with a low BMI. Study circles cover all functions in this model as described more in detail in Westergren et al. (2), and if you add a NCP, at least the evidence and facilitation parts of the model are hypothetically strengthened. Whether a combination of the 'topdown NCP' and the 'bottom-up study circles' can give even more successful results than was found here is an area for further studies.

\section{Conclusion}

Study circles with a focus on eating and nutrition give positive short-term effects, and a NCP gives positive short- and long-term effects on NC. Whether the combination of study circles and the implementation of a NCP can give even better results is an area for future studies. In addition, repeated quality controls, by means of point-prevalence studies, can possibly influence the NC positively. Thus, in order to achieve a successful intervention, one needs to work both with political anchoring, leadership (facilitators) and evidence, and with the context in which the staff is working.

\section{Conflict of interest and funding}

The authors declare that they have no competing interests.

\section{Acknowledgements}

The first author (AW) is supported by the Swedish Research Council and the Skåne County Council's research and development foundation. The study circle intervention was supported by the 'competence ladder', a government investment in competence improvement for staff in social service. We especially thank The Swedish Institute for Health Sciences (Vårdalinstitutet) for support in the development of the study circle manual focusing on eating and nutrition. The study sponsors were not involved in any parts of the study.

We thank the residents and staff, teachers and students for their cooperation. We are especially grateful to Christina Lindholm, Kerstin Ulander (deceased), and Carolina Axelsson for their contribution to the first part of the study, in 2005-2007. We also thank Karin Petersson, Anita Persson, and Liselotte Svensson for their work with implementing the interventions. The study was conducted in cooperation with the Network for Eating and Nutrition in North-East Skåne (NEN-NES) and the Clinical
Research Group within the Knowledge Group for Clinical Nursing Science at Kristianstad University.

\section{References}

1. Westergren A, Lindholm C, Axelsson C, Ulander K. Prevalence of eating difficulties and malnutrition among persons within hospital care and special accommodations. J Nutr Health Aging 2008; 12: 39-43.

2. Westergren A, Axelsson C, Lilja-Andersson P, Lindholm C, Petersson K, Ulander K. Study circles improve the precision in nutritional care in special accommodations. Food Nutr Res 2009; 53. DOI: 10.3402/fnr.v53i0.1950.

3. Labossiere R, Bernard MA. Nutritional considerations in institutionalized elders. Curr Opin Clin Nutr Metab Care 2008; 11: 1-6.

4. Cawood AL, Smith A, Dalrymple-Smith J, Bolch R, Pickles S, Church S, et al. Prevalence of malnutrition and use of nutritional support in Peterborough Primary Care Trust. J Hum Nutr Diet 2008; 21: 384.

5. Olin AO, Osterberg $\mathrm{P}$, Hådell K, Armyr I, Jerström S, Ljungqvist O. Energy-enriched hospital food to improve energy intake in elderly patients. JPEN J Parenter Enteral Nutr 1996; 20: $93-7$.

6. Turic A, Gordon KL, Craig DL, Ataya DG, Voss AC. Nutrition supplementation enables elderly residents of long-term-care facilities to meet or exceed RDAs without displacing energy or nutrient intakes from meals. J Am Diet Assoc 1998; 98: 1457-9.

7. Milne AC, Potter J, Avenell A. Protein and energy supplementation in elderly people at risk from malnutrition. Cochrane Database Syst Rev 2005; 18: CD003288.

8. Milne AC, Avenell A, Potter J. Meta-analysis: protein and energy supplementation in older people. Ann Intern Med 2006; 144: $37-48$

9. Crogan NL, Shultz JA, Adams CE, Massey LK. Barriers to nutrition care for nursing home residents. J Gerontol Nurs 2001; 27: $25-31$.

10. Simmons SF, Schnelle JF. A continuous quality improvement pilot study: impact on nutritional care quality. J Am Med Dir Assoc 2006; 7: 480-5.

11. Wikby K, Ek AC, Christensson L. Implementation of a nutritional programme in elderly people admitted to resident homes. Scand J Caring Sci 2009; 23: 421-30.

12. Bourdel-Marchasson I, Rolland C, Jutand MA, Egea C, Baratchart B, Barberger-Gateau P. Undernutrition in geriatric institutions in South-West France: policies and risk factors. Nutrition 2009; 25: 155-64.

13. Arvanitakis M, Coppens P, Doughan L, Van Gossum A. Nutrition in care homes and home care: recommendations-a summary based on the report approved by the Council of Europe. Clin Nutr 2009; 28: 492-6.

14. Kamp BJ, Wellman NS, Russell C. Position of the American Dietetic Association, American Society for Nutrition, and Society for Nutrition Education: food and nutrition programs for community-residing older adults. J Nutr Educ Behav 2010; 42: $72-82$.

15. Kuosma K, Hjerrild J, Pedersen PU, Hundrup YA. Assessment of the nutritional status among residents in a Danish nursing home-health effects of a formulated food and meal policy. J Clin Nurs 2008; 17: 2288-93.

16. Westergren A, Lindholm C, Mattsson A, Ulander K. Minimal eating observation form: reliability and validity. J Nutr Health Aging 2009; 13: 6-12.

17. SWESPEN (Swedish Society for Clinical Nutrition and Metabolism), Dietisternas Riksförbund, Nutritionsnätet för 
Sjuksköterskor och Svensk Förening för Klinisk Nutrition. Nutritionsbehandling i sjukvård och omsorg [Nutritional treatment in care and service]. ISBN 91-631-6253-9; 2006. http:// www.swespen.se [cited 17 June 2010].

18. SFS 2003 460: Lag om etikprövning av forskning som avser människor [The Act concerning the Ethical Review of Research Involving Humans on the website of the Central Ethical Review Boards]; 2003. http://www.sweden.gov.se/sb/d/3288/a/19569 [cited 17 June 2010].

19. Altman DG. Practical statistics for medical research. London: Chapman and Hall; 1991.

20. Norman GR, Streiner DL. Biostatistics. The bare essentials, 3rd ed. Shelton, CT: People's Medical Publishing House; 2008.

21. Nijs KA, de Graaf C, Siebelink E, Blauw YH, Vanneste V, Kok FJ, et al. Effect of family style mealtimes on quality of life, physical performance, and body weight of nursing home residents: cluster randomised controlled trial. BMJ 2006; 332: $1180-4$.

22. Simmons SF, Zhuo X, Keeler E. Cost-effectiveness of nutrition interventions in nursing home residents: a pilot intervention. J Nutr Health Aging 2010; 14: 367-72.

23. Beck AM, Ovesen L, Schroll M. Home-made oral supplement as nutritional support of old nursing home residents, who are undernourished or at risk of undernutrition based on the MNA.
A pilot trial. Mini Nutritional Assessment. Aging Clin Exp Res 2002; 14: 212-5.

24. Barberger-Gateau P, Rainville C, Letenneur L, Dartigues JF. A hierarchical model of domains of disablement in the elderly: a longitudinal approach. Disabil Rehabil 2000; 22: 308-17.

25. Blaum CS, Fries BE, Fiatarone MA. Factors associated with low body mass index and weight loss in nursing home residents. J Gerontol A Biol Sci Med Sci 1995; 50: M162-8.

26. Kitson AL, Rycroft-Malone J, Harvey G, McCormack B, Seers $\mathrm{K}$, Titchen A. Evaluating the successful implementation of evidence into practice using the PARiHS framework: theoretical and practical challenges. Implement Sci 2008; 3: 1. DOI:10.1186 /1748-5908-3-1.

\footnotetext{
*Albert Westergren

Department of Clinical Nursing Science

School of Health and Society

Kristianstad University

SE-29| 88

Kristianstad, Sweden

Tel: +4644208550

Email: Albert.Westergren@hkr.se
} 